\title{
Research and Application of Networked Management of University and College Graduation Paper Design
}

\author{
Sainan Zhang \\ Department of Teaching Affairs, \\ Jilin Agricultural University, \\ Changchun, China \\ Email: Zhangsainan8304@126.com
}

\begin{abstract}
Due to the increasing number of undergraduates, the management of academic papers, an important part of undergraduate education, is faced with more and more difficulties. First, previous academic papers fail to be assorted into valid data for reference, thus resulting in low management efficiency. Second, there are no strict standards for paper title selection and setting. Third, it is hard for supervisors to learn the research progress of every student, so supervisors give effective and immediate guidance and supervision. Against the backdrop, this paper puts forward a solution plan targeted at the defects existing in the modern paper management, namely the SSH comprehensive graduation paper management platform based on Java Web. The system employs the MySQL database and the user interface employs the ExtJs, JQuery and other multiple techniques. In the practical operation, the system perfectly finished the networked management pilot work of graduation paper design of students admitted by Information Technology College of Jilin Agricultural University in 2010 and received high acclaim from teachers and students with its complete functions, stable operations and friendly user interface.
\end{abstract}

Keywords-university and college; graduation paper design; networked management

\section{INTRODUCTION}

Undergraduate academic papers are important literature resources with high academic and intelligence value. With the deepening of the undergraduate enrollment work, every year witnesses the increasing number of graduates and the expansion of universities and colleges. The traditional manual management model has been faced with many problems, including lack of unified teaching management and chaos of graduation paper design procedures; inefficient graduation paper design process monitoring, lack of unity in terms of graduation paper content, format and standards; difference in supervisors' guidance style and level and lack of freedom for students to choose the research titles they are good at; lack of fairness in the marking period. All these problems seriously influence the efficiency and quality of graduation paper design and restrict the realization of the teaching management requirements under the credit system. In order to standardize the graduation paper management and evaluation, alleviate the heavy and repeated work of supervisors and defense teachers, improve the working efficiency and make supervisors devote most of their energy to guiding students' graduation paper instead of handling some onerous and repeated document work, a set of efficient and practical graduation paper design management methods are crying for to meet demands of both teachers and students.

Undergraduate graduation paper design management is an important link of teaching management work. However, there have not yet been effective management methods and tools. The current management model has the defects of high management difficulty, repeated workload, low efficiency and lack of fairness, so it cannot effectively meet the requirements of the undergraduate paper design management. Against the backdrop, the system makes full use of the computer and network resources in universities and colleges to conduct all-round management of various graduation paper design links and finally make the graduation paper design management electronized, networked, standardized and monitorable. By doing so, the graduation paper design management can improve its efficiency and better maintain fairness ${ }^{[1]}$.

\section{SYSTEM DEVELOPMENT MODEL AND FRAMEWORK}

\section{A. Development model}

The system adopts Java language as the backstage development language. The forestage combines JavaScript and JavaScript class library (JQuery and ExtJs) and MySql Server as the database, and adopts Tomcat as the server

Java is an object-oriented language, and has the advantages of cross-platform, good portability, irrelevance to hardware, robust and safe system, provision of the concurrent mechanism, high performance and availability of distributed, multithreading and dynamic support. Besides, Java is embedded with the multithreading support, which allows the simultaneous fulfilment of multiple tasks.

The system adopts the database developed by Oracle Corporation. Due to its small volume, quick speed, high security and no need for submitting charge for use, it becomes a mainstream development database. It can be matched with Tomcat to form a favorable system operation environment. Besides, the core thread of MySql is fully multi-threading, which supports multiprocessor.

Tomcat is a free and open-source Servlet vessel. It is a core project of Apache Foundation. 


\section{B. Framework design}

The system has the most mature framework structure-“"Struts2+Spring2.5+Hibernate3."

(1) Struts2 is an open source project affiliated to Apache. Over years of development, it has become the mainstream framework of MVC, and has strong expansibility, which can integrate multiple functional modules. Struts2 is upgraded from Web Work. It has the inborn advantages of Web Work. To develop applications with the framework has the advantage of clear logic and easy maintenance ${ }^{[2]}$.

(2) Spring2.5 is one of the mainstream development frameworks of Java Web. It is characterized by innovation dependency injection form (IOC or Inversion of Control), which allows the maximal decoupling of the Java program. The IOC vessel can maintain certain amount of the instantiated Java class. If the instantiated Java class is needed, it can be re-injected. This greatly improves the efficiency and reduces the system overhead of the object's repeated instantiated destruction.

(3) Hibernate3 is the most popular and commonly-used data persistence framework. It advocates the operation of the relation model through the operation method of the domain model. The use of Hibernate 3 can minimize the chances of directly encountering and operating the relation model, develop through the unified object-oriented method and reduce the cost of data migration. At the same time, Hibernate can automatically optimize the HQL statements written by users, connect the connection pool and user the cache to maximize performance.

\section{OVERALL DESIGN}

\section{A. Overall system module design}

From the perspective of users, the system can be divided into three parts. The first part is the functional module of administrators, which is involved with functions of system setting, data import and export, data inquiry statistics, database backup and recovery, research issue review, etc. The second part is the functional module of teachers, including the management of research issue, students and later process. The third part is the functional module of students, which is mainly about the selection of graduation paper title selection and periodical task submission.

From the perspective of business logics, the system can be divided into the submission and review, the selection and confirmation of the graduation paper title design, the approval and management of paper proposal, the management of the graduation paper writing schedule and the approval and management of the periodic achievements $^{[3]}$.

\section{B. General introduction of system's functional modules}

Design and realization of teachers' functional module

Teachers' test base management module: The module sets the test base to facilitate teachers' management of graduation title design. The test base is similar to teachers' private document base, which is convenient for teachers to submit the research title, and conduct statistics of the test questions designed previously.

- Teachers' title submission module: Teachers can send the research title to students of different departments and majors according to requirements. During the title submission process, teachers can choose the titles in the test base or design new ones.

- Teachers' student management module: Teachers can manage students and students' graduation papers according to different grades. module

Design and realization of students' functional

- Students' title selection module: Within the limited time, students can choose their desired research title.

- Students' paper proposal management module: After the research title is selected, students need to submit the paper proposal in time and state clearly the paper writing agenda in the proposal for the review of supervisors.

Design and realization of administrators' functional module

- Administrators' statistics functional module: Administrators need to conduct statistics of all the data about the title selection and graduation paper design schedule of different grades, which mainly include the statistics of the research titles of various grades or certain grade; statistics of students' fulfilment situation in various periods, etc $^{[4]}$.

- Administrators' paper title review module: Administrators need to investigate into the difficulty, number of applicants and repeatability of research titles submitted by teachers, and give the final review results. If the title is approved, students can see the title and choose it; otherwise, teachers are reminded to change the title.

\section{Database design}

The database needs to build corresponding data table and describe the business entities according to certain requirement. Under the prerequisite of ensuring efficiency and completeness, the database redundancy should be reduced. The major data tables of the system are listed below.

IV. DISPLAY OF SYSTEM'S MAJOR FUNCTIONAL MODULES

\section{A. System framework design}

The major system framework adopts the frameset 
segmentation, of which the left is the working area and the left is the catalog. Users' passwords conduct the encrypted transmission according to the principle of asymmetry between the public secret keys and private secret keys. The public and private secret keys are the large numerical pairs. The huge numerical value made up by the three-digit numbers can provide safe transmission ${ }^{[5]}$.

\section{B. N-level authority management model}

The N-level authority management model means different users (students, teachers and administrators) are provided with different functional catalogs. Relevant authority can be dynamically set.

\section{V.CONCLUSIONS AND FUTURE RESEARCH PROSPECTS}

Graduation paper is an important link in the higher education, so the effective paper management is increasingly important and in need. Under the background, the system is designed.

The system has finished the following functional modules, including the submission and review, the selection and confirmation of the graduation paper title design, the approval and management of paper proposal, the management of the graduation paper writing schedule and the approval and management of the periodic achievements. Now, it can provide graduation paper title selection and process tracking services for teachers and students, and store relevant data for future reference.

The system is employed to finish the networked management pilot work of graduation paper design of students admitted by Information Technology College of Jilin Agricultural University in 2010.

A complete software system calls for long-term maintenance and update, and immediate understanding of users' feedback so as to keep improving relevant functions. After collecting suggestions of teachers and students, the system aims at developing and realizing the paper defense and marking module, and providing teachers and students with the text message and E-mail service through China Mobile's SMS interface and Java Mail. This can help achieve the whole-process tracking and services of graduation paper writing.

\section{REFERENCES}

[1] Huang Weiqin. Problems in Web - based Management of College Graduation Thesis in Zhejiang and Countermeasures[J]. Journal of Ningbo University of Technology,2011(1):30-32.

[2] He Ying.Strengthening the Management of Graduation Thesis is an Important Assurance to Improve the Quality of Graduation Thesis[J]. Heilongjiang Research On Higher Education,2001(5):43-45.

[3] Zheng Qinhua, Chen Li.Thesis Management in Modern Distance Education: Present Situation and Countermeasures[J]. Modern Distance Education Research,2010(5):55-59.

[4] Fang Liang. Current Management and Measures of Economic Management Majors'Graduation Paper in Application-oriented Universities[J]. Journal of Anqing Teachers College(Social Science Edition),2014(4):156-159.
[5] Yang Fangqing.An Analysis of the Current Problems in the Management of English Majors'Graduation Theses and Countermeasures[J]. Journal of Fujian Institute of Education,2013(6):102-104. 